\title{
The Saturated Flow Modeling on Motorcycle Behavior Based on Through Movements at Signalized Intersections
}

\author{
I M Kariyana ${ }^{1, *}$, P A Suthanaya ${ }^{2}$, D M P Wedagama ${ }^{2}$, I M A Ariawan ${ }^{2}$ \\ ${ }^{1}$ Doctor of Engineering Study Program, Udayana University, Denpasar, 80361, Bali, Indonesia \\ ${ }^{2}$ Department of Civil Engineering, Faculty of Engineering, Udayana University, Denpasar, 80361, Bali, Indonesia
}

Received April 21, 2021; Revised May 24, 2021; Accepted June 25, 2021

\section{Cite This Paper in the following Citation Styles}

(a): [1] I M Kariyana, P A Suthanaya, D M P Wedagama, I M A Ariawan, "The Saturated Flow Modeling on Motorcycle Behavior Based on Through Movements at Signalized Intersections," Civil Engineering and Architecture, Vol. 9, No. 4, pp. 1189-1197, 2021. DOI: 10.13189/cea.2021.090420.

(b): I M Kariyana, P A Suthanaya, D M P Wedagama, I M A Ariawan (2021). The Saturated Flow Modeling on Motorcycle Behavior Based on Through Movements at Signalized Intersections. Civil Engineering and Architecture, 9(4), 1189-1197. DOI: 10.13189/cea.2021.090420.

Copyright $(\mathrm{C} 2021$ by authors, all rights reserved. Authors agree that this article remains permanently open access under the terms of the Creative Commons Attribution License 4.0 International License

\begin{abstract}
In developing countries such as Indonesia the proportion of motorcycles to other vehicles is reaching $76 \%$, which is very high. The proportion of motorcycles in Bali Province exceeds $85 \%$ while in Denpasar City is $82 \%$. Previous studies suggest that a high proportion of motorcycles will certainly affect the saturated flow. Therefore, the effect of motorcycles on saturation flows should not be neglected. With a high proportion of motorcycles that will affect the behavior of motorcyclists at irregular intersections such as in front of the stop line, besides other vehicles and behind other vehicles or in the flow, the behavior of the motorcycle affects the saturated flow. In calculating saturated flow, the Indonesian Highway Capacity Manual (IHCM) does not have specific measures that adopt the behavior of motorcycles. If the motorcycle is not properly regulated, it will interfere with the movement of other vehicles when the green light is on. The behavior to be examined in this study is the behavior of motorcycles in front of the stop line, outside the current (beside flow), or in the current (inside flow). In this study, a model was developed to determine saturation flow based on the behavior of motorcycles for through movements at signalized intersections with or without ESSM.
\end{abstract}

Keywords Motorcycles Behavior, Saturation Flow, Signalized Intersections, Exclusive Stopping Space for Motorcycles (ESSM)

\section{Introduction}

Studying signalized intersections is one of the most effective measures to increase road network capacity and reduce traffic congestion [6]. The management of signaled intersection traffic flow is much easier to research and analyze if all motorized vehicles are homogeneous [8]. A heterogeneous (mixed) traffic system is very different compared to that of a homogeneous one. For mixed traffic conditions, vehicle sizes and types and control also vary [22].

Mixed traffic dominated by motorcycles is very common in most Asian countries such as Taiwan, Thailand, Vietnam, Indonesia, and Malaysia. For example, the proportion of motorcycles in Hanoi and Ho Chi Minh City in Vietnam is around 90\% [6]. In Taiwan, the concept of segregated traffic flow (motorcycle lane separation) was proposed and successfully implemented to improve mixed traffic performance.

The Indonesian government is preparing Exclusive Stopping Space for Motorcycle (ESSM) at several signalized intersections, to accommodate the high number of motorcycles. ESSM is a motorcycle facility in the form of providing motorcycle facilities at signalized intersections. ESSM is an alternative solution to the problem of motorcycle congestion at signalized intersections. When entering the green time signal, motorcycles move with various maneuvers to get out of the approach to the intersection, so that it often creates traffic conflicts which 
are thought to affect the performance and flow of traffic movements at the intersection [12].

A better understanding of the impact of motorcycles on traffic flow affects the development of a more accurate model to determine the effect of motorcycles on the saturated flow [6]. Saturation flow plays an important role in the design of a signalized intersection [18]. The saturation flow (S) is the amount of queue departure in an approach during the specified conditions (pcu/green hour). Meanwhile, the basic saturation flow is the amount of queue departure in the approach during ideal conditions (pcu/green hour) [13].

As a reference for determining intersection parameters such as saturated flow and capacity in Indonesia, the Indonesian Highway Capacity Manual (IHCM) was published in 1997. In 1997, the composition of motorcycles for urban areas in Indonesia was at an average of $40.5 \%$ [13], which is very different from the current condition. It was found that based on the preliminary survey, the composition of motorcycles in Denpasar City was $82 \%$. Although Indonesian urban areas have a high percentage of motorcycles, there has been no adjustment to IHCM regarding the high percentage of motorcycles, the number of vehicle ownership, and the behavior of motorcycles in Indonesia. The IHCM determines the saturation flow based on the basic saturation flow times the adjustment factor. Besides that, the passenger car equivalent (PCE) value does not reflect the real conditions in the field, either. The PCE value has been determined, for example, the PCE for motorcycle is 0.2 , the PCE for the light vehicle is 1 and the PCE for the heavy vehicle is 1.3 , without any PCE analysis at each intersection studied. Improper regulation of motorcycles, especially at intersections, will not only reduce the level of service at intersections but may also lead to an increase in road traffic accidents.

The behavior of the motorcycle users at a signalized intersection has affected saturated flows, especially motorcycles in the current (inside flow), the greater the composition of the motorcycle in the flow, the higher the saturation flow [11]. According to the $[9,14,16$, ], the behavior of motorcycles at signalized intersections can be grouped into several categories, namely motorcycles in front of the stop line, motorcycles inside flows, and motorcycles outside the flows (beside flow). This study examines the behavior of motorcycles towards saturated flow on through movements because in Denpasar City for large traffic flows, the arrangement of intersections with more signals is done through movement to reduce conflict at signalized intersections. Through movements are free movements that are not affected by conflict $[18,19]$ while according to $[2,20]$ through movements are movements (turn right, go straight, turn left) in each approach that is given the green light simultaneously, and given 1 phase per approach so that vehicles turning right do not have to wait to enter opposite traffic. In this study, what is meant by through movement is the movement of traffic at an intersection approach that has 1 phase or an intersection whose approach has the same phase as other approaches but the movement does not affect or be influenced by the movements of other approaches.

The study of traffic flow at signalized intersections is a new topic. Several studies have been conducted to examine saturated flow and capacity, aimed at improving traffic conditions at signalized intersections or across the transportation network. However, from previous research, no one has determined the influence model of motorcycle behavior at signalized intersections, namely the behavior of motorcycles in front of the stop line, inside flow (inside flow) and outside flow (beside flow), both those with ESSM and without ESSM to saturated flows. Motorcycle behavior research conducted in Malaysia by Leong et al. [11] and in Ghana by Adams et al. [1] only analyzed the effect of motorcycle behavior in the flow (inside flow) without analyzing the behavior of motorcycles in front of the stop line and outside the flow (beside flow) and does not analyze the differences in behavior at the signalized intersections that have ESSM or without ESSM. There are also many kinds of research related to ESSM, such as research by [3-7], but no research has analyzed the effect of motorcycle behavior with and without ESSM on saturation flow. Most of the studies only examined the effectiveness of ESSM based on the effect of total motorcycles on saturated flows. This study aims to determine the effect of motorcycle behavior on saturation flow based on through movements at signalized intersections that are partially or simultaneously dominated by motorcycles. This benefits to establishing regulations associated with motorcycles at signalized intersections, inclusive of designing the ESSM, creating separate lanes among motorcycles and other vehicles, and setting up the traffic signal. In this research, we will obtain a model or formula to determine the saturation flow only by knowing the behavior of motorcycles at signalized intersections that are dominated by motorcycles. This study also provides suggestions for overcoming the accumulation of vehicles at signalized intersections that are dominated by motorcycles which may apply to other areas that have the same characteristics, both the geometric and the proportions of the motorcycles. A model of motorcycle behavior towards saturated flow was developed, both with and without ESSM.

\section{Materials and Methods}

The regression method is more relevant for the estimation of saturation flow at signalized intersections because its implementation of calculations is easier and simpler. However, this technique relies heavily on accurate estimation of saturation flow which is also a function of determining PCE [15]. To obtain an accurate saturation flow estimation, the method of determining the saturation flow at signalized intersections in this study is used by 
Chang and Xiao [5]. Traditional methods that only use the average discharge headway to estimate the saturation headway can lead to underestimation. Errors in the saturated flow used for the estimation of vehicle delays can cause errors in the prediction of delay and Level of Service (LOS). Therefore, it is necessary to conduct a study to increase the accuracy of the saturation flow estimation. The facts show that driver behavior is the main determinant of saturation flow. Therefore, a good understanding of the time between discharge headways is essential in estimating the time between saturation headway and saturation flow rate. The stochastic properties of the time between vehicle releases could provide better information for the development of a method of estimating saturation flow rates [5]. It is easy to understand that the time between vehicle releases is a random variable due to differences in driver behavior response times and variations in queue space length. To estimate the saturation headway time, the average time between vehicle releases is calculated as follows:

$$
\overline{h_{S}}=\frac{1}{n} \sum_{i=1}^{n} h_{S i}
$$

With,

$h_{s}$ : the average time between discharges $(s)$ which is taken as the estimated time between saturations $h$;

$h_{s i}$ : time between vehicles $i$ in the queue, $i=1,2, \ldots$, $n$ ( $n$ is the sample size), consequently, the level of saturation flow is (conventionally) determined by the time between discharge:

$$
S=\frac{3600}{\bar{h}_{S}}
$$

With,

$S$ is the saturation flow level (vehicle/hour).

Based on the statistical theory that "If the intermediate time distribution is symmetric, the average intermediate time calculated by equation (1) is a good (unbiased) estimate of $h$ and equation (2) can be a good estimate for the saturation flow rate" [14]. However, if the intermediate time distribution is not symmetrical, $h_{S}$ is not a good estimate, and equation (2) will give a saturation flow level value that is too high (overestimate) or too low (underestimate). Therefore, it is necessary to study the stochastic nature of the time between queuing vehicles and to analyze the effect of time variation between the estimated saturation flow rates [5].

When the mean time between queue releases is greater than the median value and the skewness of the intermediate time values is positive, this characteristic indicates that the time distribution between queue releases tends to be asymmetrical and the normal distribution function does not match the intermediate time data [5]. Therefore, the conventional saturation flow rate estimation method (equation 2) can produce an underestimated saturation flow level value.

If the time distribution between queue releases tends to be asymmetrical, then the intermediate time value can be modeled with a lognormal distribution $[5,17]$. If it is known that when the random variable $h_{S}$ function density is lognormal, then $\ln h_{S}$ will follow the normal distribution. Therefore, it is very relevant to use the median value to calculate the saturation flow rate in the following way:

$$
S_{1}=3600 \times \frac{1}{h_{\text {med }}}
$$

With,

$S_{1}$ : a new estimate of the saturation flow rate (vehicles/hour);

$h_{m e d}:$ the median value of the intermediate time or the estimated median value of the intermediate time.

In addition, there are two new estimates for the saturation flow rate [14]

$$
\begin{gathered}
S_{2}=3600 \times \exp \left(-\frac{1}{n} \sum_{i=1}^{n} \ln h_{S i}\right) \\
S_{3}=\frac{3600}{\bar{h}_{S}} \times\left(1+\frac{\sigma_{S}^{2}}{\bar{h}_{S}^{2}}\right)^{0.5}
\end{gathered}
$$

With,

$S_{2}$ and $S_{3}$ are two new estimates of the saturation flow rate (vehicles/hour).

$$
\sigma_{S}^{2}=\left[\frac{1}{n}-1 \cdot \sum_{i=1}^{n}\left(h_{S i}-\bar{h}_{S}\right)^{2}\right]
$$

represents the variance of the intermediate time sample.

The selected intersection has a large volume of motorcycles, namely 82 percent [4]. Minor side barriers, namely interference from factors such as pedestrians, vehicles turning left or right, parking vehicles (on-street parking), and bus stops or stops, both those with ESSM and those without ESSM are at one of the intersection approaches. The intersection chosen is also one of the approaches that have a through movement of motorcycles or is not affected by conflict, whether there is an ESSM or no ESSM.

This study was conducted in Denpasar City. Based on data obtained from the Denpasar City Department of Transportation, Denpasar City has 66 intersections with signals, of which 15 intersections have Exclusive Stopping Space for Motorcycle and 51 intersections have no ESSM [10]. For the analysis, an approach has been chosen at the four signalized intersections which have approximately the same volume of vehicles passing through the intersection. The same approach width has the proportion of motorcycles that reflect the same mixed traffic flow conditions between the existing ESSM and those without the ESSM, as shown in Table 1. Discharge Headway data is obtained from video recordings of the Denpasar City Area Traffic Control System (ATCS), data retrieval is conducted for 2.5 hours during the morning, afternoon, and evening peak hours. 


\section{Results and Discussion}

Headway data were obtained from the Denpasar City Area Traffic Control System (ATCS) video recordings, which include 9440 headway data for an approach with an effective width of 3 meters with ESSM and 10833 without ESSM. Discharge headway data from the approach of the effective width of 5 meters with ESSM as much as 14161 and without ESSM 19667 data. Discharge headway data from the approach of the effective width of 7 meters with ESSM as much as 14002 and without ESSM 14932 data. Discharge headway data from each approach were combined into one for each approach width, both with ESSM and without ESSM to get the saturated flow value.

In Table 2, it can be seen that the proportion of vehicles in each approach with an approach width of 3 meters, 5 meters, and 7 meters, both with ESSM and without ESSM. Based on Table 2, the percentage of the proportion of motorcycles is relatively the same as the 1-2 percent difference between the approach with ESSM and without ESSM except for the 3 meters width of the approach. There is a difference of $5.6 \%$ of the approach without ESSM. The percentage of motorcycles is greater compared to those with the ESSM approach.

Meanwhile, the percentage of motorcycle behavior in each approach, both with ESSM and without ESSM, is shown in Table 3. Based on Table 3, motorcycles at a signalized intersection tend to behave beside flow (beside other vehicles), both those with ESSM and without ESSM, which happens because motorcycles have more freedom to maneuverer because there are no light vehicles in front of them. The percentage of the behavior of motorcycles beside flow is greater than inside flow at a signalized intersection with ESSM, whether the approach width is 3 meters, 5 meters, or 7 meters.

Furthermore, the headway data analysis was carried out in SPSS descriptively as well as knowing the form of data distribution. The purpose of this analysis is to see whether data distribution patterns are normally distributed or not. The form of data distribution can be determined through statistical calculations with the Shapiro-Wilk or Kolmogorov Smirnov approach. According to the data, less than 50 uses the Shapiro Wilk approach, while more than 50 use the Kolmogorov-Smirnov. The data is said to be normally distributed if the Sig. from the test statistic is greater than 0.05 .

Table 1. Intersections with the same Approach Width and Traffic Characteristics

\begin{tabular}{|c|c|c|c|c|c|}
\hline \multirow{2}{*}{ No. } & \multirow{2}{*}{ Approach Width (m) } & \multicolumn{2}{|c|}{ Intersection } & \multicolumn{2}{|c|}{ Approach } \\
\hline & & With ESSM & Without ESSM & With ESSM & Without ESSM \\
\hline \multirow{2}{*}{1} & \multirow{2}{*}{7} & Dewi Sartika & Kebo Iwa & Dewi Sartika & Gatot Subroto Barat (T) \\
\hline & & Dewi Sartika & Kebo Iwa & Teuku Umar & Gatot Subroto Barat (B) \\
\hline \multirow{3}{*}{2} & \multirow{3}{*}{5} & & Saelus & & Diponegoro (S) \\
\hline & & Kapten Japa & Surabi & Hayam Wuruk (T) & Supratman (B) \\
\hline & & Kapten Japa & Kenyeri & Hayam Wuruk (B) & Gatot Subroto Tengah (B) \\
\hline \multirow{2}{*}{3} & \multirow{2}{*}{3} & Nangka & Perumnas & Nangka (U) & Buana Raya \\
\hline & & Unud & Saelus & Serma Mendra & Pulau Saelus \\
\hline
\end{tabular}

Table 2. The proportion of vehicles in each approach with and without ESSM

\begin{tabular}{ccccc}
\hline \multirow{2}{*}{ Approach Width } & \multicolumn{3}{c}{ Vehicle } \\
\cline { 3 - 5 } & & Motor cycle & Light Vehicle & High \\
Vehicle
\end{tabular}

Table 3. Percentage of motorcycle behavior of each approach with and without ESSM

\begin{tabular}{ccccc}
\hline \multirow{2}{*}{ Approach Width } & \multicolumn{3}{c}{ Motorcycle Behaviour } \\
\cline { 3 - 5 } & & In front of the stop line & Beside flow & Inside flow \\
\hline \multirow{2}{*}{$3 \mathrm{~m}$} & Non ESSM & 3,06 & 75,45 & 22,24 \\
& ESSM & 1,61 & 79,54 & 19,18 \\
\hline \multirow{2}{*}{$5 \mathrm{~m}$} & Non ESSM & 1,87 & 50,20 & 48,86 \\
& ESSM & 1,46 & 65,62 & 33,43 \\
\hline \multirow{2}{*}{$7 \mathrm{~m}$} & Non ESSM & 4,03 & 55,20 & 42,58 \\
& ESSM & 0,42 & 57,16 & 42,61 \\
\hline
\end{tabular}


Data with normal distribution were calculated to obtain the saturation flow with Formula 2, while data that were not normally distributed, were calculated using the Formula (3, $4,5)$. Based on the observations on the saturation flow values at $S_{1}, S_{2}$, and $S_{3}$, the saturation flow values are almost the same. This result is also confirmed by [10] who simulated the calculations using the $S_{1}, S_{2}$, and $S_{3}$ formula approaches. Based on the results of this analysis, a similar saturation flow value is obtained, so it can be concluded that the $S_{1}, S_{2}$, or $S_{3}$ values can be selected for use by the researcher.

This study uses the $S_{3}$ formula for data that is not normally distributed because the $S_{3}$ formula is the final development of the previous formula and the formula accommodates the size of the center (mean) and data distribution (variance).

3M Wide Approach without ESSM

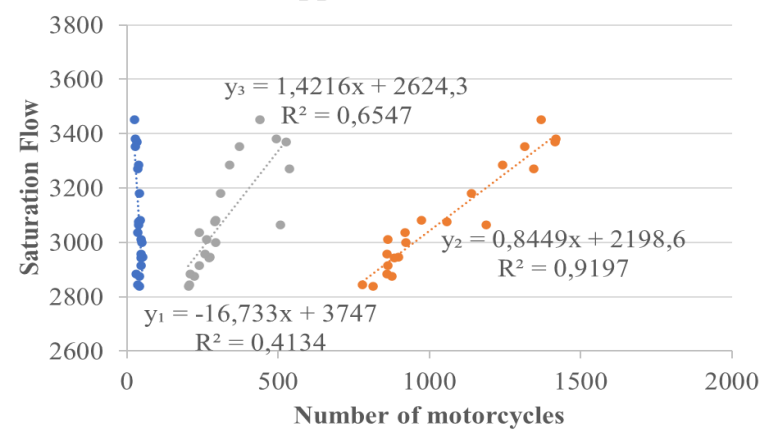

5M Wide Approach without ESSM

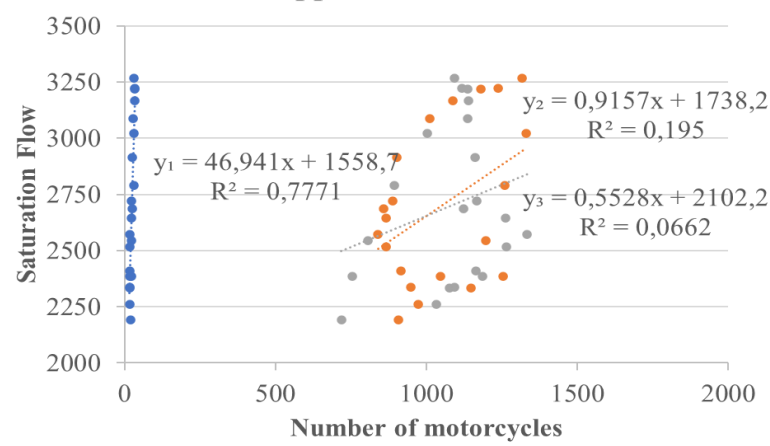

7M Wide Approach without ESSM

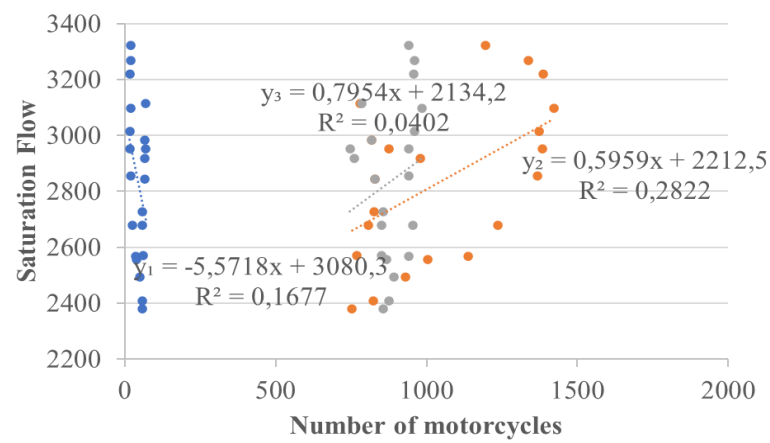

After the $S$ value is obtained based on the various criteria above, then a behavioral analysis of the saturation flow is carried out by using multiple linear regression. The analysis is divided into two, namely as a whole (behavior of motorcycles inside flow, In front of a stop line, and beside flow) to saturated flow and their respective behavior by ignoring other behaviors (behavior of the infront motorcycles to saturated flow, behavior of motorcycles beside saturated flow and the behavior of the inside motorcycle to saturated flow). The model obtained is then evaluated based on the value of its fit model using the $\mathrm{R}$-Square approach and F-count ( $\mathrm{F}$ significance). A model whose fit model is good, deserves to be interpreted, while a model whose fit model is still weak is considered not feasible. For the model of the influence of behavior individually by ignoring other behaviors, a model is obtained as shown in Figure 1.

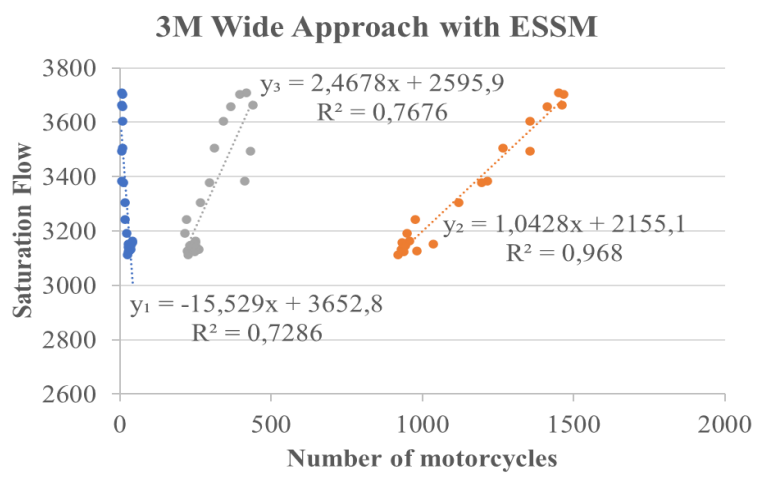

5M Wide Approach with ESSM

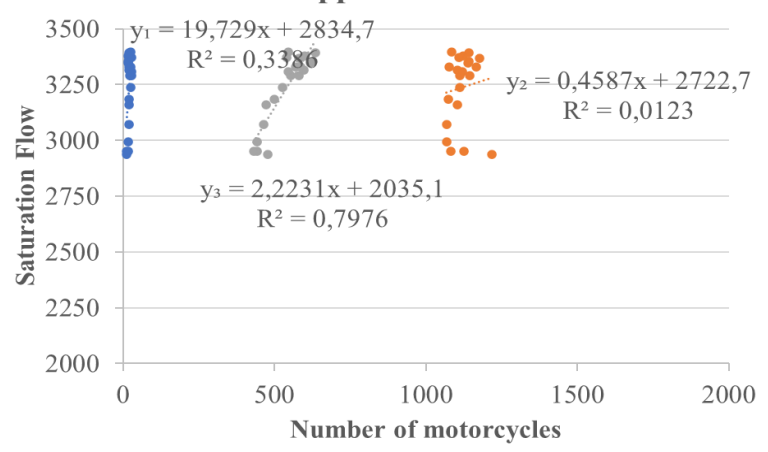

7M Wide Approach with ESSM

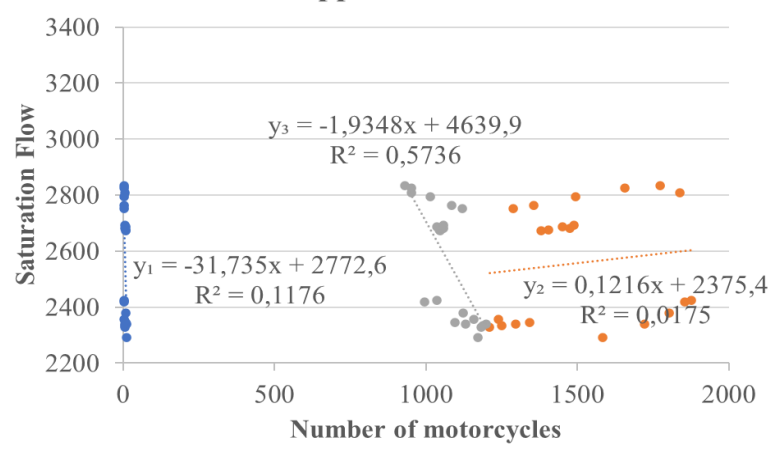

Infront

Beside

Inside — Linear (Infront)

- Linear (Beside)

- Linear (Inside)

Figure 1. The model of the influence of each motorcycle behavior on saturated flow ignores the influence of other behaviors 
The regression model at a signalized intersection with an approach width of 3 meters without ESSM or with partial ESSM by only taking into one behavior and ignoring other behaviors, it is found that the behavior of in front of a stop line, inside flow and beside flow has an effect on saturated flow. The regression model at a signalized intersection with an approach width of 5 meters without ESSM shows only that the behavior in front of stop line and beside affects saturated currents, while the width of the approach of 5 meters with ESSM shows that only the behavior of in front of stop line and inside flow affects saturated flow. The regression model at a signalized intersection with an approach width of 7 meters without ESSM shows only that beside flow affects saturation flow, while the width of the approach of 7 meters with ESSM shows that only inside flow affects the saturation flow.

Table 4 shows the relationship between the effect of motorcycle behavior on saturated flow and an approach width of 3 meters, 5 meters, and 7 meters without ESSM. Meanwhile, table 5 shows the relationship between the effect of motorcycle behavior on saturated flow and the approach width 3 meters, 5 meters, and 7 meters with ESSM.

The regression model at the intersection with a signal with an approximate width of 3 meters without ESSM taking into account all behaviors in the analysis (In front of a stop line, inside flow, and beside flow). The regression analysis model in Non-ESSM 3 produces goodness of fit value with the R-Square approach of 0.945 and the significance of $\mathrm{F}$ is 0.000 . The significance value of $\mathrm{F}$ obtained is greater than 0.05 , which means that the model built based on the data obtained is feasible. The R-Square value of 0.945 indicates that there is an effect of motorcycle behavior on saturation flow of $94.5 \%$, while the remaining $5.5 \%$ is influenced by other factors outside the three independent variables at the intersection with a signal without ESSM with an approach width of 3 meters. Partially, a significance value is obtained at the Infront of 0.38 , which means that there is no influence on the behavior of motorcycles in front of the stop line on saturated flow, but there are differences between beside flow and inside flow, which respectively get a significance value of 0.000 and 0.013 where beside and inside has a significant effect on saturation flows at the intersection with no ESSM signal with a width of 3 meters. The model for the saturation flow is obtained:

$\mathrm{S}=1968.85+1.92 \mathrm{MC}$ Infront of stop line+1.21 MC beside-

The regression model at the intersection with a 3 meters wide approach with ESSM produces goodness of fit value with the R-Square approach of 0.972 and a significance of $F$ of 0.000 . The significance value of $\mathrm{F}$ obtained is greater than 0.05 , which means that the model built based on the data obtained is feasible. The R-Square value of 0.972 indicates that there is an effect of motorcycle behavior on saturation flow of $97.2 \%$, while the rest is influenced by other factors outside the three independent variables.

Table 4. Model of influence of motorcycle behavior at signalized intersections without ESSM

\begin{tabular}{cccc}
\hline Statistics & Non ESSM 3 & Non ESSM 5 & Non ESSM 7 \\
\hline \multirow{2}{*}{ Model } & $\mathrm{Y}=1968.85+1.92 \mathrm{X} 1+1.21 \mathrm{X} 2-$ & $\mathrm{Y}=346.31+46.78 \mathrm{X} 1+$ & $\mathrm{Y}=5710.93-7.79 \mathrm{X} 1+0.90 \mathrm{X} 2-$ \\
& $0.7 \mathrm{X} 3$ & $0.27 \mathrm{X} 2+0.86 \mathrm{X} 3$ & $3.93 \mathrm{X3}$ \\
\hline R-Squared & 0.945 & 0.915 & 0.464 \\
\hline Sig. F & 0.000 & 0.000 & 0.012 \\
\hline Constant & 1968.85 & 346.31 & 5710.93 \\
\hline \multirow{3}{*}{ Uns. Coeff. } & Infront (X1):1.92 & Infront (X1): 46.78 & Infront (X1):-7.79 \\
\cline { 2 - 4 } & Beside (X2): 1.21 & Beside (X2): 0.27 & Beside (X2): 0.90 \\
\hline & Inside (X3): -0.7 & Inside (X3): 0.86 & Inside (X3): -3.93 \\
\cline { 2 - 4 } Sig. t & Infront (X1): 0.38 & Infront (X1): 0.000 & Infront (X1): 0.55 \\
& Beside (X2): 0.000 & Beside (X2): 0.15 & Beside (X2): 0.21 \\
\cline { 2 - 4 } & Inside (X3): 0.013 & Inside (X3): 0.000 & Inside (X3): 0.084 \\
\hline
\end{tabular}

Table 5. Model of influence of motorcycle behavior at signalized intersections with ESSM

\begin{tabular}{cccc}
\hline Statistics & ESSM 3 & ESSM 5 & ESSM 7 \\
\hline \multirow{2}{*}{ Model } & $\mathrm{Y}=2017.18+0.14+1.19-0.42 \mathrm{X} 3$ & $\mathrm{Y}=2131.43+10.61 \mathrm{X} 1-$ & $\mathrm{Y}=5748.76+4.35 \mathrm{X} 1-0.35 \mathrm{X} 2-$ \\
& $0.18 \mathrm{X} 2+2.01 \mathrm{X} 3$ & 0.574 \\
\hline R-Squared & 0.972 & 0.901 & 0.000 \\
\hline Sig. F & 2107.18 & 0.000 & 5748.76 \\
\hline Constant & Infront (X1):0.14 & 2131.43 & Infront (X1):4.35 \\
\hline \multirow{2}{*}{ Uns. Coeff. } & Beside (X2): 1.19 & Infront (X1): 10.61 & Beside (X2): -0.35 \\
\cline { 2 - 4 } & Inside (X3): -0.42 & Beside (X2): -0.18 & Inside (X3):- 2.5 \\
\cline { 2 - 4 } & Infront (X1): 0.928 & Inside (X3): 2.01 & Infront (X1): 0.755 \\
\cline { 2 - 4 } Sig. t & Beside (X2): 0.000 & Infront (X1): 0.003 & Beside (X2): 0.034 \\
\cline { 2 - 4 } & Inside (X3): 0.16 & Beside (X2): 0.65 & Inside (X3): 0.000 \\
\hline
\end{tabular}


Partially, a significance value is obtained for the Infront of 0.928 and the inside flow of 0.158 , which means that there is no influence on the behavior of motorcycles in the Infront of the stop line and inside flow on saturated flow. However, there are differences between beside flow, obtaining a significance value of 0.000 , where beside has a significant effect on saturated flow at a signalized intersection with ESSM with a 3 meters wide approach. The model for the saturation flow is obtained:

$$
\begin{gathered}
\mathrm{S}=2017.18+0.14 \mathrm{MC} \text { Infront of stop line+1.19 MC } \\
\text { beside- } 0.42 \text { MC Inside }
\end{gathered}
$$

The regression model at a signalized intersection with an approximate width of 5 meters without ESSM results in a goodness of fit value with the R-Square approach of 0.915 and a significance of $F$ of 0.000 . The significance value of $\mathrm{F}$ obtained is greater than 0.05 , which means that the model built based on the data obtained is feasible. The R-Square value of 0.915 indicates that there is an influence of motorcycle behavior on saturation flow of $91.5 \%$, while the rest is influenced by other factors outside the three independent variables. Partially, it is obtained a significance value beside flow of 0.15 which means there is no influence of the behavior of motorcycles beside flow on saturated flow, However, in contrast to in front of stop line and inside flows, it obtained a significance value of 0.000 where the infront of stop line and inside flow contributed significantly to the saturated flow at the signalized intersection without ESSM with an approach width of 5 meters. The model for the saturation flow is obtained:

$$
\begin{gathered}
\mathrm{S}=346.31+46.78 \mathrm{MC} \text { Infront of stop line }+0.27 \mathrm{MC} \\
\text { beside }-0.86 \mathrm{MC} \text { Inside }
\end{gathered}
$$

The regression model at the signalized intersection with an approximate width of 5 meters with ESSM produces goodness of fit value with the R-Square approach of 0.901 and a significance of $\mathrm{F}$ of 0.000 . The significance value of $\mathrm{F}$ obtained is greater than 0.05 , which means that the model built based on the data obtained is feasible. The R-Square value of 0.901 indicates that there is an influence of motorcycle behavior on saturation flow of $90.1 \%$, while the rest is influenced by other factors outside the three independent variables. Partially, it is obtained a significant value beside flow of 0.65 , which means that there is no influence of the behavior of motorcycles beside flow on saturated flow, However, in contrast to the infront of stop line and inside flow, it has a significant value of 0.003 and 0.000 where the infront of stop line and inside flow have a significant effect on saturated flow at the signalized intersection with ESSM with a 5 meters wide approach. The model for the saturation flow is obtained:

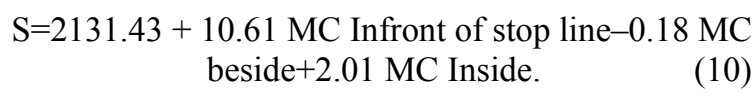

The regression model at the signalized intersection with an approach width of 7 meters without ESSM results in a goodness of fit value with the R-Square approach of 0.464 and a significance of $\mathrm{F}$ of 0.012 . The significance value of $\mathrm{F}$ obtained is greater than 0.05 , which means that the model built based on the data obtained is feasible. The R-Square value of 0.464 indicates that there is an effect of motorcycle behavior on the saturated flow of $46.4 \%$, while the rest is influenced by other factors outside the three independent variables. Partially, the significant values of the infront of stop line, beside flow and inside flow are obtained, respectively $0.549,0.206$, and 0.084 , which means that there is no influence on the behavior of motorcycles, infront of stop line, beside flow and inside flow separately. The model for the saturation flow is obtained:

$$
\begin{array}{r}
\mathrm{S}=5710.93-7.79 \mathrm{MC} \text { In front of stop line }+0.90 \mathrm{MC} \\
\text { beside }-3.93 \mathrm{MC} \text { Inside }
\end{array}
$$

The regression model at a signalized intersection with an approximate width of 7 meters with ESSM produces goodness of fit value with the R-Square approach of 0.574 and a significance of $F$ of 0.000 . The significance value of $\mathrm{F}$ obtained is greater than 0.05 , which means that the model built based on the data obtained is feasible. The R-Square value of 0.574 indicates that there is an effect of motorcycle behavior on the saturated flow of $57.4 \%$, while the rest is influenced by other factors outside the three independent variables. Partially, the Infront of stop line significance value is 0.755 , which means that there is no effect of the behavior of motorcycles in front of the stop line on saturated flows, However, it is different with beside and inside flows, obtaining a significance value of 0.034 and 0.000 where beside and inside flows have a significant effect on saturated flow at the signalized intersection with ESSM with a 7 meters wide approach. The model for the saturation flow is obtained:

$$
\begin{gathered}
\mathrm{S}=5748.76+4.35 \mathrm{MC} \text { Infront of stop line- } 0.35 \mathrm{MC} \\
\text { beside }-2.5 \mathrm{MC} \text { Inside }
\end{gathered}
$$

The addition of the number of motorcycles that are in the inside flow of the approach which has a lane width of 3 meters and 7 meters with and without ESSM can reduce saturation currents. Increasing the number of motorcycles on the front of the stop line can reduce the saturation current in the approach with 7 meters lane width without ESSM. The increase in the number of motorcycles on the beside flow reduces the saturated current in the approach with a lane width of 5 meters and 7 meters with ESSM.

\section{Conclusions}

This model of the effect of saturated flow on motorcycle behavior applies to through movement with traffic conditions dominated by motorcycles, the percentage of motorcycles is $76 \%$ to $90 \%$ and the effective width of the approach is 3 meters, 5 meters, and 
7 meters with or without ESSM. The model generated from the regression analysis of the influence of motorcycle behavior (infront of stop line, beside flow, and inside flow) together produces a better model than the model obtained from the regression analysis separately, namely the effect of the behavior of motorcycles on the infont of stop line on saturated flow, the effect of the behavior of motorcycles beside flow on saturated flow and the influence of the behavior of motorcycles inside flow on saturated flow.

Concerning the ESSM at signalized intersections, motorcycle behavior must be considered as that highly influences the saturation flow. The application of ESSM in Denpasar, Bali needs to be reviewed because the presence or absence of ESSM does not necessarily affect the saturation flow. The ESSM in Denpasar, Bali is currently unable to accommodate a large number of motorcycles at a signalized intersection, so special lanes are needed by motorcycles. At the intersection with 3 meters width of approach with or without motorcycle ESSM, the motorcycle beside flow affects the saturation flow the most, so it is necessary to make a motorcycle lane on the left or right of another vehicle. Whereas for a signal intersection with a $5 \mathrm{~m}$ lanes width with and without ESSM and a $7 \mathrm{~m}$ lanes width with the ESSM of the motorcycle inside the most influencing the saturated flow so that a motorcycle lane is needed in the middle of another vehicle.

By knowing the behavior of motorcycles at a signalized intersection with an approach width of 3 meters, 5 meters, 7 meters with or without ESSM, the saturation flow can be determined without counting the number of light or heavy vehicles, especially for the 3 and 5 meters approach widths. Further research is needed with conditions like this in other cities, so that better results can be obtained

\section{Acknowledgments}

I am very grateful to Ngurah Rai University for its support. We are grateful to anonymous reviewers for their valuable comments on the earlier version of this paper.

\section{REFERENCES}

[1] Adams C., .Abdul M.., Zambang M.., \& Boahen R, "Effects of motorcycles on saturation flow rates of mixed traffic at signalized intersections in Ghana," International Journal of Traffic and Transportation Engineering, vol. 4, no. 3, pp. 94-101, 2015.

[2] Al-Ghamdi A, "Entering headway for through movements at urban signalized intersections," Transportation Research Record, vol. 1678, no. 1, pp. 42-47, 1999. DOI: $10.3141 / 1678-06$

[3] Amelia S., Juanita, "Effectiveness of Application of Special
Stop Rooms (Rhk) at Urban Road Intersections (Case Study: Bandung City Pasteur-Pasirkaliki Road Intersection)," Techno Scientific Magazine, vol. 12, no. 2, pp. 64-100, 2011.

[4] Central Bureau of Statistics of Bali Province. "Bali in Numbers." Central Bureau of Statistics of Bali Province, https://bali.bps.go.id/publication/2019/08/16/99cd2c6d79a adla0062dddfc/provinsi-bali-dalam-angka-2019.html (accessed Jan. 28, 2020).

[5] Chang Qiao Shao, Xiao Ming Liu, "Estimation of Saturation Flow Rates at Signalized Intersections," Discrete Dynamics in Nature and Society, vol. 2012, pp. 1-9, 2012. DOI: $10.1155 / 2012 / 720474$

[6] Chu Cong Minh, Kazushi Sano, "Analysis of Motorcycle Effects to Saturation Flow Rate at Signalized Intersection in Developing Countries," Journal of the Eastern Asia Society for Transportation Studies, vol. 5, no. 10, pp. 1211-1222, 2003.

[7] Fadli S., Elkhasnet, "Comparison of the Value of Saturated Flow in the Simpang Approach with and without Exclusive Stopping Space for Motorcycle," Transportation Journal, vol. 12, no. 3, pp. 217-226, 2012.

[8] H. Nguyen., F. Montgomery, "Different Models of Saturation Flow in Traffic Dominated by Motorcycles," Journal of the Eastern Asia Society for Transportation Studies, vol. 7, no. 2002, pp. 2381-2395, 2007. DOI: $10.11175 /$ easts. 10.1734

[9] Hongwei Li, Xin Zhong, Wenbo Zhang, Sulan Li, Yingying Xing, "An algorithm for e-bike equivalents at signalized intersections based on traffic conflict events number," Transportation Research Part A: Policy and Practice, vol. 134, no. 4, pp. 78-95, 2012. DOI: 10.1016/j.tra.2020.02.007

[10] I. M. Kariyana, G. Sumarda., N. P. G. Swarupini, "Inventory and Evaluation of Exclusive Stopping Space for Motorcycle (ESSM) Motorcycles in Denpasar City," Gradient Engineering Journal, vol. 12, no. 2, pp. 16-24, 2020.

[11] Leong Lee Vien, Wan Hashim Wan Ibrahim, Ahmad Farhan Mohd, "Effect of Motorcycles Travel Behaviour on Saturation Flow Rates at Signalized Intersections in Malaysia," 23rd ARRB Conference - Research Partnering with Practitioners, Adelaide Australia, 2008, 1-11.

[12] Ministry of Public Works and Public Housing, "Guidelines for Designing Special Stopping Rooms (RHK) for Motorcycles at Signalized Intersections in Urban Areas." Ministry of Public Works and Public Housing. http://sni.litbang.pu.go.id/index.php?r=/sni/new/sni/detail/i d/1044 (accessed Jan. 28, 2020).

[13] Ministry of Public Works, "Signaled Intersection," in Indonesian Road Capacity Manual (IRCM), Directorate General of Highway, 1997, pp. 2-38.

[14] Ministry of Works Malaysia, "Chapter 3," in Malaysian Highway Capacity Manual 2006, [10] Ministry of Works Malaysia, 2006.

[15] Mithun Mohan., Satish Chandra, "Queue Clearance Rate Method for Estimating Passenger Car Equivalents at Signalized Intersections," Journal of Traffic and Transportation Engineering, vol. 4, no. 5, pp. 487-495, 2017. 
DOI: $10.1016 /$ j.jtte.2016.12.003

[16] Mohmmad Rameez, Sandeep Singla, Manish Kaushal, "A Study on Discharge Headway Modeling at a Signalized Intersection under Heterogeneous Traffic Conditions," International Journal for Research in Applied Science and Engineering Technology (IJRASET), vol. 6, no. X pp. 232-238, 2018.

[17] Mohsin Shahzad Chaudhry, Prakash Ranjitkar, Douglas J. Wilson, "Queue Discharge Behavior at Signalized Intersection: A Comparison Between Field Measurements with Analytical and Microsimulation Models," Journal of the Eastern Asia Society for Transportation Studies, vol. 9, no. 2011, pp. 1628-1643, 2011. DOI: 10.11175/easts. 9.1628

[18] Partha Saha., H. M. Iqbal Mahmud., Quazi Sazzad Hossain, MD. Zahurul Islam, "Passenger car equivalent (PCE) of through vehicles at signalized intersections in Dhaka metropolitan city, Bangladesh," IATSS Research, vol. 33, no. 2, pp. 99-104, 2009. DOI: $10.1016 / \mathrm{S} 0386-1112(14) 60248-\mathrm{X}$
[19] Saad Touhbi, Mohamed Ait Babram, Tri Nguyen-Huu, Nicolas Marilleau, Moulay L. Hbid, Christophe Cambier, Serge Stinckwich, "Time Headway analysis on urban roads of the city of Marrakesh," Procedia Computer Science, vol. 130, no. 2018, pp. 111-118, 2018. DOI: 10.1016/j.procs.2018.04.019

[20] Satyajit Mondal, Ankit Gupta, "Discharge characteristics analysis of queued-up vehicles at signal-controlled intersections under heterogeneous traffic conditions," International Journal of Civil Engineering, vol. 17, no. 5, pp. 619-628, 2018. DOI: 10.1007/s40999-018-0343-7

[21] Satyajit Mondal, Vijai Kumar Arya, Ankit Gupta, Samsi Gunarta, "Comparative analysis of saturation flow using various PCU estimation methods," Transportation Research Procedia, vol. 48, no. 2020, pp. 3153-3162, 2020. DOI: 10.1016/j.trpro.2020.08.168

[22] I Wayan Suweda, D. M Priyantha Wedagama , "The Influence of Motorcycles on Discharge Headway and Saturation Flows at Signalized Intersections under Mixed Traffic Conditions," Civil Engineering and Architecture, Vol. 9, No. 3, pp. 595 - 604, 2021. DOI: 10.13189/cea.2021.090303. 